\title{
PENGARUH PENAMBAHAN TUMBUKAN CANGKANG KEONG MAS TERHADAP KUAT TEKAN BETON NON STRUKTUAL K-175
}

\author{
Sugeng Dwi Hartantyo ${ }^{2}$,Muhammad Hakim Susianto ${ }^{2}$, \\ ${ }^{1,2}$ Fakultas Teknik Universitas Islam Lamongan. \\ Email:sugeng.dwih@gmail.com;kemsar237@gmail.com,
}

\begin{abstract}
He aim of the research is to find out the process of making mash snail shells and the concrete compressive strength and to find out the process of testing the concrete compressive strength on the mash shell conch collision. The research design is the process of collecting and analyzing research data. Medote This research includes planning and conducting research. For planning design begins with observation and evaluation of research that has been carried out and has been known, until the formation of the framework requires further evidence. In this research method, it also includes making experiments or observations, and also has measurement variables, techniques and procedures, data collection, data analysis, collecting data, and reporting research results. This research uses mash shell conch additive material which aims to determine the effect of mash snail shell addition to the compressive strength of concrete with a percentage variation of $2 \%, 4 \%$, and $6 \%$ by weight of cement. The results of collisions of mas snail shells on concrete mixtures with additional variations of $2 \%(15,423), 4 \%(17,59)$ and $6 \%$ $(19,276)$, where the highest compressive strength values were obtained by adding $6 \%$ of snail shell shells, 19,276 Mpa, while the lowest value is in the addition of mash snail shell collision 2\%, which is 15,423 Mpa.
\end{abstract}

Keywords: Concrete, Compressive Strength, Non Structural K-175, Conch Shell Waste

\begin{abstract}
ABSTRAK
Tujuan peneliantian Untuk mengetahui proses pembuatan tumbukan cangkang keong mas terdahap kuat tekan beton dan.Untuk mengetahui proses pengujian kuat tekan beton pada penamahan tumbukan cangkang keong mas. Rancangan penelitian adalah proses pengumpulan dan analisis data penelitian. Medote Penelitian ini meliputi perencanaan dan melakukan penelitian. Untuk rancangan perencanaan diawali dengan observasi dan evaluasi penelitian yang telah dilakukan dan telah dikenal, sampai pembentukan kerangka diperlukan bukti lebih lanjut. Dalam metode penelitian ini termasuk juga membuat eksperimen atau pengamatan, dan juga memiliki variabel pengukuran, teknik dan prosedur, pengumpulan data, analisis data telah mengumpulkan sempel, dan pelaporan hasil penelitian. Penelitian ini menggunakan bahan tambah tumbukan cangkang keong mas terhadap yang bertujuan untuk mengetahui pengaruh penambahan tumbukan cangkang keong mas terhadap kuat tekan beton dengan variasi persentase 2\%, 4\%, dan 6\% dari berat semen. Hasil dari data tumbukan cangkang keong mas pada campuran beton dengan variasi penambahan 2\% (15,423), 4\% (17,59), dan 6\% (19,276), dimana nilai kuat tekan tertinggi didapat pada penambahan tumbukan cangkang keong mas 6\% yaitu 19,276 Mpa, sedangkan nilai terendah terdapat pada penambahan tumbukan cangkang keong mas $2 \%$ yaitu 15,423 Mpa.
\end{abstract}

Kata kunci : Beton, Kuat Tekan, Non Struktural K-175, Limbah Cangkang Keong Mas

\section{PENDAHULUAN}

\subsection{Latar Belakang}

Beton adalah sebuah bahanbangunankomposityang terbuat dari kombinasi aggregat dan pengikat semen. Bentuk paling umum dari beton adalah beton semen Portland, yang terdiri dari agregat mineral (biasanya kerikil dan pasir), semen dan air,Biasanya dipercayai bahwa beton 
mengering setelah pencampuran dan peletakan. Sebenarnya, beton tidak menjadi padat karena air menguap, tetapi semen berhidrasi, mengelem komponen lainnya bersama dan akhirnya membentuk material seperti-batu. Beton digunakan untuk membuat perkerasan jalan, struktur bangunan, fondasi, jalan, jembatan penyeberangan, struktur parkiran, dasar untuk pagar/gerbang, dan semen dalam bata atau tembok blok. Nama lama untuk beton adalah batu cair.

Keong Mas (Pomacea canaliculata) mengandung kadar $\mathrm{CaCO} 3$ (kalsium karbornat) yang sangat tinggi, sehingga dapat bereaksi sangat baik dengan semen sebagai bahan utama pembuatan beton. Kalsium karbornat ialah senyawa kimia dengan formula $\mathrm{CaCO} 3$,senyawa ini merupakan bahan yang umum dijumpai pada batu,cangkang organisme laut,keong mas(siput),bola arang, mutiara, dan kulit telur

\subsection{Tujuan Penelitian}

Tujuan dari penelitian ini adalah :

1. Untuk mengetahui pengaruh tumbukan tumbukan cangkang keong mas terdahap kuat tekan beton.

2. Untuk mengetahui proses pengujian kuat tekan beton K- 175 pada penamahan tumbukan cangkang keong mas

\section{METODE PENELITIAN}

\subsection{Rencana Penelitian}

Metode penelitian ini dilakukan dengan cara pengujian di Laboratorium sesuai dengan datadata dari studi pustaka menggunakan standart SNI beton. Sampel yang dibuat adalah beton segar dengan perbandingan komposisi campuran yang menggunakan serbuk batu gamping sebagai campuran beton.

Bahan yang di gunakan dalam penelitian ini adalah semen Portland, air, agregat halus, agregat kasar, bahan tambah dan tumbukan cangkang keong mas, Adapun benda uji berupa cetakan beton silinder untuk mencetak beton yang akan diuji dalam penelitian campuran beton menggunakan tumbukan cangkang keong mas sebagai bahan campuran beton, uji bahan kimia dan kuat tekan beton akan dilakuan untuk mengatahui kandungan bahan kimia dalam campuran beton dan berapa kekuatan beton tersebut. Benda uji akan diuji dalam 7 hari, dalam kurung waktu ini akan diketahui nilai tertinggi untuk setiap pengujian yang telah dilakukan. Metode penelitian yang digunakan adalah job mix design dengan menggunakan standart SNI 03-28342000 dengan mutu beton.

\subsection{Lokasi dan Waktu Penelitian}


Waktu dan tempat penelitian ini akan dilakukan dilaboratorium Teknik Sipil Universitas Islam Lamongan Jl. Veteran No.53 A Lamongan, benda uji penelitian ini adalah kuat tekan beton non struktural yang sebagaimana campuranya adalah serbuk batu gamping.

\subsection{Teknik Pengumpulan Data}

Sumber data penelitian di dapat dari hasil laboratorium Program Study Teknik Sipil Fakultas Teknik Universitas Islam Lamongan sesuia dengan data-data dari study pustaka standart Indonesia SK SNI maupun standart asing yaitu ASTM.

\subsection{Analisis Data}

Analisis data juga dapat didefinisikan sebagai suatu kegiatan yang dilakukan untuk mengubah data hasil dari penelitian menjadi sebuah informasi baru yang dapat digunakan dalam membuat kesimpulana. membuat data hasil pengujian semen, agregat kasar, agregat halus dan kuat tekan beton.

Sumber data penelitian di dapat dari hasil laboratorium Program Study Teknik Sipil Fakultas Teknik Universitas Islam Lamongan sesuia dengan data - data dari study pustaka standart Indonesia SK SNI maupun standart asing yaitu ASTM.

\subsection{Flow}

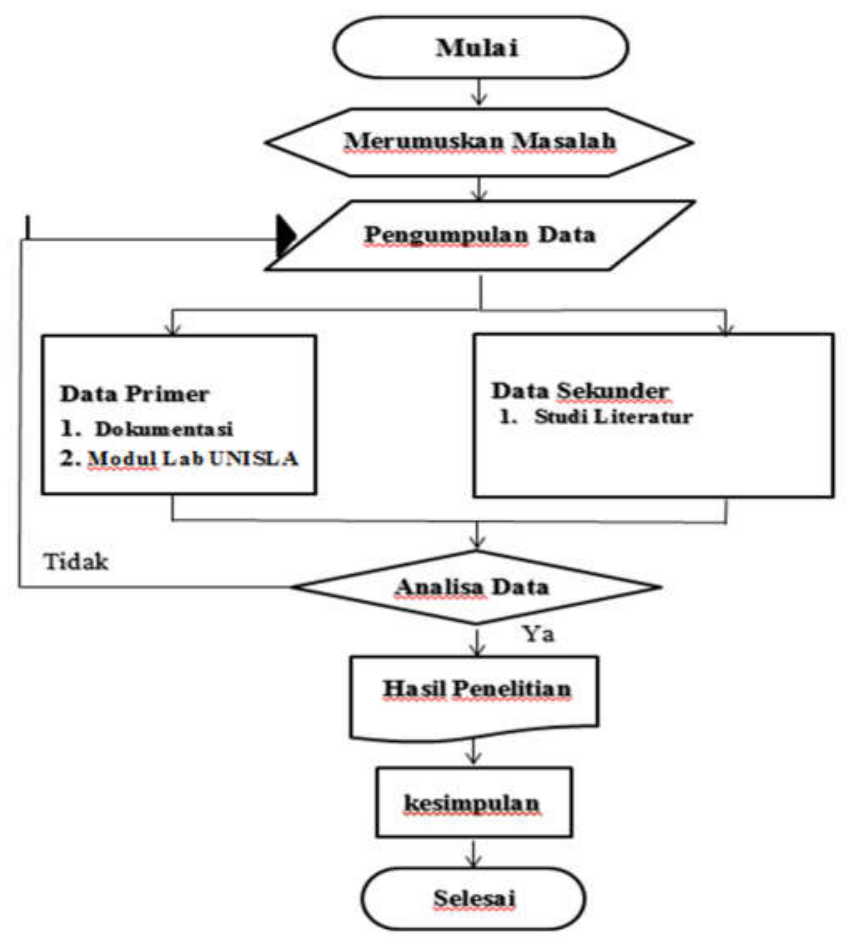

\section{HASIL DAN PEMBAHASAN}

\subsection{Proses Pembuatan Benda Uji}


Pelaksanaan penelitian dibagi menjadi beberapa tahap, diawali dengan persiapan dan pengujian bahan, pembuatan dan perawatan benda uji, dilanjutkan dengan pengujian bahanyang mengacu pada ASTM (American Standard Testing and Material) dan pembuatan beton pada standar yang berlaku sesuai SNI-03-2834-2000, pengujian di laksanakan di Laboratorium Teknik Sipil Universitas Islam Lamongan. Data-data yang di uji meliputi :

1. Penyediaan bahan tambah tumbukan cangkang keong mas.

2. Pengujian semen meliputi :

a. Pengujian konsistensi normal semen portland

b. Pengujian waktu mengikat dan mengeras semen

c. Pengujian berat jenis semen

3. Pengujian pasir (Agregat Halus) meliputi :

a. Pengujian analisa saringan distribusi ukuran butir / gradasi pasir

b. Pengujian kadar air agregat halus

c. Pengujian berat jenis pasir pada kondisi SSD

d. Pengujian kadar air resapan pasir

e. Pengujian berat volume pasir baik dalam keadaan lepas maupun terikat.

4. Pengujian batu pecah (Agregat Kasar) meliputi :

a. Pengujian analisa saringan distribusi ukuran butir / gradasi batu pecah

b. Pengujian kelembapan batu pecah

c. Pengujian berat jenis batu pecah pada kondisi SSD

d. Pengujian kadar air resapan kerikil

e. Pengujian berat volume batu pecah baik dalam keadaan lepas maupun terikat.

5. Proses pembuatan beton meliputi :

a. Proses perhitungan bahan campuran beton

b. Proses persiapan bahan

c. Proses pencampuran beton dengan bahan tambah tumbukan cangkang keong mas

d. Pengujian slump test

e. Proses pencetakan beton

6. Penimbangan beton segar meliputi :

a. berat beton normal

b. berat beton dengan campuran tumbukan cangkang keong mas $2 \%$

c. berat beton dengan campuran tumbukan cangkang keong mas $4 \%$

d. berat beton dengan campuran tumbukan cangkang keong mas $6 \%$

7. Proses pembongkaran cetakan beton

8. Proses perawatan beton (curing) 


\subsection{Proses Perhitungan Bahan Campuran Beton}

Tabel 3.1 Kebutuhan Bahan Untuk Beton Normal

\begin{tabular}{|ccc|}
\hline Jenis Bahan & Berat & Satuan \\
\hline Semen Portland & 11,64 & $\mathrm{Kg}$ \\
Pasir & 10,85 & $\mathrm{Kg}$ \\
Krikil & 25,318 & $\mathrm{Kg}$ \\
Air & 4,88 & Liter \\
\hline
\end{tabular}

Tabel 3.2 Perhitungan Campuran Tumbukan Cangkang Keong Mas 2\%

\begin{tabular}{|ccc|}
\hline Jenis Bahan & Berat & Satuan \\
\hline Semen Portland & 11,41 & $\mathrm{Kg}$ \\
Pasir & 10,85 & $\mathrm{Kg}$ \\
Krikil & 25,318 & $\mathrm{Kg}$ \\
Air & 4,88 & Liter \\
Tumbukan Cangkang Keong \\
Mas
\end{tabular}

Tabel 3.3 Perhitungan Campuarn 4\%

\begin{tabular}{|ccc|}
\hline Jenis Bahan & Berat & Satuan \\
\hline Semen Portland & 11,17 & $\mathrm{Kg}$ \\
Pasir & 10,85 & $\mathrm{Kg}$ \\
Krikil & 25,318 & $\mathrm{Kg}$ \\
Air & 4,88 & Liter \\
$\begin{array}{c}\text { Tumbukana Cangkang Keong } \\
\text { Mas }\end{array}$ & 0,46553 & $\mathrm{Kg}$ \\
\hline
\end{tabular}

Tabel 3.4 Perhitungan Campuarn 6\%

\begin{tabular}{|lll|}
\hline Jenis Bahan & Berat & Satuan \\
\hline
\end{tabular}




\begin{tabular}{|ccc|}
\hline Semen Portland & 10,94 & $\mathrm{Kg}$ \\
Pasir & 10,85 & $\mathrm{Kg}$ \\
Krikil & 25,318 & $\mathrm{Kg}$ \\
Air & 4,88 & Liter \\
Tumbukan Cangkang & 0,69829 & $\mathrm{Kg}$ \\
Keong Mas & & \\
\hline
\end{tabular}

Tabel 3.5 Hasil Cek Slump

\begin{tabular}{|cccc|}
\hline No & $\begin{array}{c}\text { Presentasi } \\
(\%)\end{array}$ & $\begin{array}{c}\text { Bahan } \\
\text { Tambah (kg) }\end{array}$ & $\begin{array}{c}\text { Tinggi Slump } \\
(\mathbf{c m})\end{array}$ \\
\hline 1 & $0 \%$ & - & $8 \mathrm{~cm}$ \\
2 & $5 \%$ & 0,38875 & $8,5 \mathrm{~cm}$ \\
3 & $10 \%$ & 0,7775 & $10 \mathrm{~cm}$ \\
4 & $15 \%$ & 1,166 & $12 \mathrm{~cm}$ \\
\hline
\end{tabular}

Proses Pembongkaran Cetakan

Setelah pelaksanaan campuran beton dan mencetaknya dalam silinder unuran 15 x $30 \mathrm{~cm}$ beton akan didiamkan dalam 1 hari untuk menunggu kering agar bisa dibongkar, jika silinder tidak diolesi dengan oli maka beton akan menempel di cetakan dan sulit untuk dilakukan pembongkaran.

\section{Proses Perawatan (Curring)}

Untuk proses curring air yang digunakan menggunakan air tawar biasa tidak mengandung kadar garam yang tinggi maupun air yang keruh atau bercampur dengan lumpur karena dapat mempengaruhi kekuatan beton pada saat uji kuat tekan yang akan dilakukan setelah proses curring berlangsung yaitu 7 hari perendaman.Untuk perendaman yang perlu diperhatikan selain kebersihan air juga kandungan kadar garam, penyusutan air juga juga harus selalu dipantau.

\section{KESIMPULAN}

Berdasarkan dari penjelasan pada bab-bab sebelumnya tumbukan cangkang keong mas sebagai bahan campuran beton di uji dari kuat tekan dapat disimpulkan sebagai berikut : 
1. Langkah-langkah proses pembuatan limbah cangkang keong mas, sebagai bahan campuran beton, sebagai berikut :

a. Siapkan limbah cangkang keong mas

b. Kemudian cuci bersih cangkang keong mas.

c. Setelah dicuci bersih cangkang keong mas, tumbuk cangkang keong mas dengan cara manual hingga menjadi serbuk.

d. Kemudian mengayak hasil tumbukan cangkang keong mas.

2. Peranan tumbukan cangkang keong mas yang menggantikan sebagian semen sangat berpengaruh terhadap kuat tekan beton. Hasil data tumbukan cangkang keong mas pada campuran beton pengaruh penambahan tumbukan cangkang keong mas terhadap kuat tekan beton dengan variasi persentase $2 \%, 4 \%$, dan $6 \%$ dari berat semen. Hasil dari data tumbukan cangkang keong mas pada campuran beton dengan variasi penambahan $2 \%$ $(15,423), 4 \%(17,59)$, dan 6\% $(19,276)$, dimana nilai kuat tekan tertinggi didapat pada penambahan tumbukan cangkang keong mas 6\% yaitu 19,276 Mpa, sedangkan nilai terendah terdapat pada penambahan tumbukan cangkang keong mas $2 \%$ yaitu 15,423 Mpa.

\section{Refrensi}

[1] Abdullah M., dan Kartikasari D., 2018. Evaluasi Kuat Desak Beton Mutu K-200 Dengan Menggunakan Engregat Kasar Dari Kecamatan Mantup Dan Penambahan Serat Alami Enceng Gondok. Program Studi Teknik Sipil Fakultas Teknik, Universitas Islam Lamongan.

[2] Amri, Sjafei. 2005. “Teknologi Beton”. Jakarta : Universitas Indonesia Press (UIP).

Arbi, 2015. Menggunakan Limbah Kulit Kerang Sebagai Angregat Halus. Jakarta:

[3] ASTM C.33, "Standard Specification for Concrete Aggregates", Annual Books of ASTM Standards, USA, 2002.

[4] ASTM C.330, "Standard Specification for Lightweight Aggregates for Structural Concrete", Annual Books of ASTM Standards ,USA, 2002.

[5] ASTM C.39 - 01, "Standard Test for Compressive Strength of Cylindrical Concrete", Annual Books of ASTM Standards ,USA, 2002.

[6] ASTM C.78 - 02, "Standard Test Method for Flexural Strength of Concrete Using Simple Beam with Third-Point Loading”, Annual Books of ASTM Standards ,USA, 2002.

[7] ASTM C.1240 - 01, "Standard Spesification for Use of Silica Fume as a Mineral Admixture in Hydraullic Cement Concrete and Mortar", Annual Books of ASTM Standards, USA, 2002.

[8] ASTM C496-96. Standart Test Method for Splitting Tensile Strength of Cylindrical Concrete Specimens, ASTM Internasional, USA. 
[9] Audina, A 2018. Pengaruh Cangkang Telur Terhadap Kuat Tekan Beton. Bandung

[10] Ansari, dkk 2017. Tambahan Serbuk Cangkang Telur Sebagai Penggangti Semen (ESP). Yogyakarta

[11] Arbi, 2015. Menggunakan Limbah Kulit Kerang Sebagai Angregat Halus. Jakarta

[12] Audina, A 2018. Pengaruh Cangkang Telur Terhadap Kuat Tekan Beton. Bandung

[13] Ansari, dkk 2017. Tambahan Serbuk Cangkang Telur Sebagai Penggangti Semen (ESP). Yogyakata

[14] Candra, Agata Iwan, Edy Gardjito, Yosef Cahyo, and Ginta Aditiya Prasetyo. 2019. "Pemanfaatan Limbah Puntung Rokok Filter Sebagai Bahan Campuran Beton Ringan Berpori." UKaRsT 3 (1): 82-89.

[15] Candra, Agata Iwan. n.d. "ANALISIS DAYA DUKUNG PONDASI STROUS PILE PADA PEMBANGUNAN GEDUNG MINI HOSPITAL UNIVERSITAS KADIRI Agata." Ukarst 1: 63-70.

[16] Dinas Pekerjaan Umum, 1989. SK SNI S 04 - 1989 - F Spesifikasi Agregat sebagai Bahan Bangunan, Yayasan LPMB. Jakarta.

[17] Hastutik, 2015. Teknologi Beton, Pengaruh Subtitusi Cangkang Keong Mas Dengan Kapur Terhadap Nilai Kuat Geres Tanah Pada Lempung Ekspansif, Bandung

[18] Japanese Industrial Standard (JIS) A 5905-2003 Hardboard S20 dan JIS A 5908 (2003)

[19] Japan Society of Civil Engineers. Standard Spesifications for Concrete Structures2002, Materials and Construction. Japan. 2002.

[20] Kardiyono Tjokrodimulyo, 2007. Penambahan Air Untuk Beton

[21] Kardiyono Tjokrodimulyo, 2007. Uji Kuat Tekan Beton

[22] K. Mounika, dkk., 2014. Influence Of Sea Shells Powder Onblack Cotton Soil Dduring Stabilization. Makasar

[23] Kardiyono Tjokrodimulyo, 2007. Bahan Dan Praktek Beton

[24] Mulyono, Tri, 2003. Teknologi Beton, Yogyakarta: Penerbit CV. Andi Offset

[25] Mulyono, Tri, 2004. Teknologi Beton, Yogyakarta: Penerbit CV. Andi Offset

[26] Murdrock, L.J. dan Brook, K.M., 1979. Bahan dan Praktek Beton, Jakarta: Penerbit Erlangga

[27] Micheal, 2017. Abu Cangkang Telur Sebagai Tambahan Semen (ARC). Palembang

[28] SNI 03-2834-2000 Tata Cara Pembuatan Rencana Campuran Beton Normal, Badan Standarisai Nasional.

[29] SNI 15-2049-1994 Semen Portland untuk Campuran Beton Badan Standardisasi Nasional, Indonesia. 
[30] SNI 03-2816-1992 Agregat Halus Sebagai Bahan Campuran Beton Badan Standardisasi Nasional, Indonesia.

[31] SNI 03-6817-2002 Penambahan Air sesuai Ph Badan Standardisasi Nasional, Indonesia.

[32] SNI 03-2495-1991 Bahan Tambahan Kimia untuk Beton Badan Standardisasi Nasional, Indonesia.

[33] SNI 03-2460-1991 Bahan Tambahan Mineral Fly Ash,Pozzolan, Silica Fum Badan Standardisasi Nasional, Indonesia.

[34] SNI 03-1974-1990. Metode Pengujian Kuat Tekan Beton, Badan Standarisasi Nasional.

[35] SNI 03-1968-1990, (1990).Tata Cara Pengujian Analisis Saringan Agregat Halus Dan Kasar. Jakarta: Badan Standarisasi Nasional BSN

[36] SNI (2002) :Metode Pengujian Waktu Ikat Awal Semen Portland Dengan Menggunakan Alat Vicat Untuk Pekerjaan Sipil,03-6827-2002, Badan Standardisasi Nasional, Indonesia.

[37] Sahari dan Mijan, 2011. Menggunkan Cangkang Kerang Dalam Bentuk Kepingan Dan Serbuk. Bandung

[38] Sunarto dan Affandi, N., A., 2018. Evaluasi Kuat Desak Beton Non Struktural Dengan Menggunkan Fariasi Agregat Kasar Mantup Dengan Penambahan Serat Alami Enceng Gondok. Program Studi Teknik Sipil Fakultas Teknik, Universitas Islam Lamongan.

[39] Sudarso I., dan Hepiyanto, R., 2018. Kajian Bahan Tambah Alternative Serat Enceng Gondok Terhadap Campuran Latasir Sand Sheet Kelas A Spesifikasi Seksi-6 2010 Binamarga. Program Studi Teknik Sipil Fakultas Teknik, Universitas Islam Lamongan.

[40] Tjokrodimuljo, K., 1996, Teknologi Beton, Yogyakarta: Penerbit Nafigiri

[41] Tjokrodimuljo, K., 2007, Teknologi Beton, Yogyakarta: Biro Penerbit Teknik Sipil Keluarga Mahasiswa Teknik Sipil dan Lingkungan, Universitas Gadjah Mada

[42] Tjokrodimuljo, Kardidjono,1996.Teknologi Beton. Yogyakarta: Penerbit Naviri 